\title{
Mutants of Xanthomonas oryzae pv. oryzae Deficient in General Secretory Pathway Are Virulence Deficient and Unable to Secrete Xylanase
}

\author{
Suvendra K. Ray, R. Rajeshwari, and Ramesh V. Sonti \\ Centre for Cellular and Molecular Biology, Uppal Road, Hyderabad-500007, India \\ Accepted 6 January 2000.
}

\begin{abstract}
Xanthomonas oryzae pv. oryzae (Xoo) causes bacterial leaf blight, a serious disease of rice. A virulence- and xylanasedeficient mutant of $\mathrm{Xoo}$ was isolated following ethyl methane sulfonate (EMS) mutagenesis. A cosmid clone that restored virulence and xylanase secretion was obtained from a genomic library by functional complementation. Transposon mutagenesis and marker exchange studies revealed genes on the cloned DNA that were required for xylanase production and virulence. Sequence analysis with transposon-specific primers revealed that these genes were homologues of xps $\mathrm{F}$ and $x p s \mathrm{D}$, which encode components of a protein secretion system in Xanthomonas campestris pv. campestris. Enzyme assays showed xylanase accumulation in the periplasmic space and cytoplasm of the xps $F$ mutant and the complementing clone restored transport to the extracellular space.
\end{abstract}

Additional keywords: type II protein secretion.

Xanthomonas oryzae pv. oryzae (Xoo) is the causal agent of bacterial leaf blight, a serious disease of rice. It is a vascular pathogen that grows in the xylem vessels and causes drying of infected leaves. Previously reported virulence-deficient mutants of Xoo include spontaneous mutants that lack extracellular polysaccharide (Eps) (Rajeshwari et al. 1997), mutations in $r p f C$, which encodes a regulator of pathogenicity factor production and causes Eps deficiency (Tang et al. 1996), Hrp (hypersensitive response and pathogenicity) mutants, which are unable to elicit a hypersensitive response (HR) on nonhost plants (Kamdar et al. 1993; White et al. 1995), mutations in certain avirulence (avr) genes (Leach et al. 1996), and particular Xoo auxotrophs (Yamasaki et al. 1964). We are using a genetic approach to identify other virulence functions of Xoo.

This paper discusses the isolation of a virulence- and xylanase-deficient mutant (referred to as BXO801) of Xoo and a genomic clone that restored both xylanase and virulence proficiency to this mutant. Transposon mutagenesis of the cloned DNA with either Tn5 or Tn10 and marker exchange techniques were used to define regions in the cloned Xoo DNA that are required for virulence and xylanase production. Se-

Corresponding author: Ramesh V. Sonti; Telephone: 91-40-7172241; Fax: 91-40-7171195; E-mail: sonti@ccmb.ap.nic.in

Nucleotide and/or amino acid sequence data are available at GenBank data base under accession numbers AF190907 and AF190908. quencing of these regions with outwardly directed primer sequences specific to the transposon revealed that the genes involved were homologues of $x p s \mathrm{~F}$ and $x p s \mathrm{D}$, which encode components of a protein secretion system in Xanthomonas campestris pv. campestris. $(X c c)$. We report here the requirement for a general secretory pathway (GSP; also known as type II protein secretion system) in Xoo virulence and the secretion of xylanase through this system to the extracellular environment.

\section{RESULTS}

Isolation of virulence deficient Xoo mutants.

An ethyl methane sulfonate (EMS) mutagenesis protocol that resulted in $99.9 \%$ lethality was used to generate a collection of mutants of BXO43 strain (Table 1) of Xoo. The frequency of auxotrophs in the collection was $7 \%$, frequency of pigment deficient mutants was $0.1 \%$, and frequency of Epsdeficient mutants was approximately $10 \%$. Ten out of 200 $\mathrm{Eps}^{+}, \mathrm{Pig}^{+}$, colonies were virulence deficient $\left(\mathrm{Vir}^{-}\right)$following inoculation onto rice leaves (see Materials and Methods). Lesion lengths caused by these mutants (e.g., BXO801; Fig. 1) varied between 2 and $7 \mathrm{~cm}, 17$ days after inoculation (DAI), whereas the lesion caused by the wild-type strain (BXO43) was $20 \mathrm{~cm}$. Three out of the $10 \mathrm{Vir}^{-}$mutants were auxotrophs; reversion analysis proved their virulence was due to auxotrophy (data not shown). The HR phenotype of the seven prototrophs was assessed by infiltrating Xoo strains in tomato leaves as described in Materials and Methods. One strain out of the seven (BXO802) did not elicit HR whereas the other six mutants were $\mathrm{HR}^{+}$. They also grew as well as the wild type when plated on peptone sucrose agar (PSA) or minimal media, suggesting that the virulence deficiency was not due to any general growth deficiency. Exponentially growing cultures of these six mutants were as motile as wild type when observed under the light microscope. One of these mutants, called BXO801, was taken up for this study.

The BXO801 mutant is xylanase deficient.

The production of extracellular enzymes like cellulases, pectinases, and proteases has been correlated with virulence in several Gram-negative, plant-pathogenic bacteria (Andro et al. 1984; Roberts et al. 1988; Schell et al. 1988; Tang et al. 1987). Our laboratory wild-type strain, BXO1, did not produce detectable levels of extracellular proteases, pectinases, or cellu- 
lases when assayed as described in Materials and Methods. The BXO1 strain, however, produced a secreted xylanase and the BXO801 mutant did not show xylanase activity (Fig. 2). The other EMS-induced, virulence-deficient mutants were all xylanase proficient (data not shown).

\section{Isolation of a clone that restores both xylanase and virulence proficiency to BXO801.}

Clones from a cosmid genomic library of BX01 were mobilized to the BXO801 strain in 26 pools of 12 clones each (as described in Materials and Methods). The transconjugants obtained on selection plates were inoculated on rice plants, and one donor pool that restored virulence to BXO801 was identified. Testing of the individual clones in that pool resulted in isolation of clone pSR1, which restored virulence to BXO801 (Fig. 1). Complete restoration was not observed, probably in part due to instability of the complementing clone in the absence of antibiotic, since only $50 \%$ of the bacteria recovered from the leaf 17 DAI retained the clone. The pSR1 clone also restored xylanase production to BXO801 (Fig. 2). Restriction map of the cloned DNA was generated with EcoRI, HindIII, and BamHI (Fig. 3). Four EcoRI fragments of $11.0,9.0,6.2$, and $3.5 \mathrm{~kb}$ were present on the insert. Digestion of Xoo genomic DNA and pSR1 DNA with EcoRI and hybridization with pSR1 revealed identical insert bands, indicating that the cloned DNA was from the Xoo genome. The organization of the insert DNA in pSR1 was shown to be same as in the genomic DNA with other restriction enzymes, such as BamHI and HindIII (data not shown).

\section{Functional mapping of pSR1 by transposon mutagenesis and marker exchange.}

The pSR1 clone was subjected to mutagenesis with mini Tn5 and mini Tn10 elements (see Materials and Methods). The transposon insertions were mapped to the cloned DNA by restriction analysis (Fig. 3). Tn5 mutagenesis of pSR1 resulted in two insertions in the 11-kb ( $z x x-102$ and $z x x-103)$ and two in the 9-kb EcoRI fragments ( $z x x-101$ and vir-2). None of these four insertions affected complementation of BXO801 for either xylanase production or virulence. Also, marker exchange of three of these insertions in the wild type background did not affect either xylanase production or virulence. However, one marker exchange mutant (BXO808) with transposon insertion (vir-2::Tn5) in the 9-kb fragment was not affected for xylanase production but was reduced for virulence. The mutant showed lesion lengths of approximately 2 and 8 $\mathrm{cm} 10$ and 17 DAI, respectively, compared with 15 and $24 \mathrm{~cm}$ caused by the wild-type strain. The mutant strain also exhibited an altered lesion phenotype (data not shown).

Eleven Tn10 insertions were also isolated on cloned DNA in pSR1 and insertions were mobilized into the BXO801 background to study their effect on complementation for virulence as well as xylanase proficiency. One insertion (xpsF1::Tn 10) in the 3.5-kb fragment (Fig. 3) affected com-

Table 1. Bacterial strains and plasmids ${ }^{\mathrm{a}}$

\begin{tabular}{|c|c|c|}
\hline Strain & Relevant characteristics & Reference \\
\hline \multicolumn{3}{|c|}{ Escherichia coli strains } \\
\hline DH5 $\alpha$ & $\begin{array}{l}\mathrm{F}^{\prime} \text {, end A1 hsdR17 }\left(\mathrm{rk}^{-} \mathrm{mk}^{+}\right) \text {supE44 thi-1 recA1 gyrA relA1 } \phi 80 \mathrm{dlacZ} \Delta \mathrm{M} 15 \Delta \\
\text { (lacZYA-argF) U169 }\end{array}$ & Lab collection \\
\hline S17-1 & RP4-2-Tc::Mu-Km::Tn7 pro hsdR recA & Simon et al. 1983 \\
\hline LE392 & supF supE hsdR galK trpR metB lacY tonA & Lab collection \\
\hline MC4100 & $\mathrm{F}^{\prime} \Delta$ (argF-lac) U169 rpsL 150 relA1 araD139 flbB5301 deoC1 ptsF25 & Lab collection \\
\hline MG1655 & Wild type & Singer et al. 1995 \\
\hline CAG18431 & MG1655 ilv-500::Tn 10 & Singer et al. 1995 \\
\hline \multicolumn{3}{|l|}{ Plasmids } \\
\hline pUFR034 & $\mathrm{IncW} \mathrm{Nm}^{\mathrm{r}} \mathrm{Mob}^{+} \mathrm{mob}(\mathrm{P}) \mathrm{lacZa}^{+} \mathrm{Par}^{+} \cos (8.7 \mathrm{~kb})$ & DeFeyter et al. 1990 \\
\hline pRK600 & pRK2013 npt::Tn9; $\mathrm{Cm}^{\mathrm{r}}$ & Lab collection \\
\hline PBluescript (KS) & $\mathrm{Ap}^{\mathrm{r}}$ & Stratagene, La Jolla, CA \\
\hline pSR1 & $\begin{array}{l}\text { pUFR034 + 30-kb insert from BXO1 genome (complements BXO801 for virulence } \\
\text { and xylanase production) }\end{array}$ & This study \\
\hline pSR2 & pUFR034 + 3.5-kb EcoRI fragment of the insert from pSR1 & This study \\
\hline \multicolumn{3}{|c|}{ Xanthomonas oryzae pv. oryzae strains } \\
\hline $\mathrm{BXO1}$ & Laboratory wild type & Lab collection (an Indian is olate) \\
\hline BXO43 & rif-2, Rif $^{\mathrm{T}}$ derivative of $\mathrm{BXO} 1$ & Lab collection \\
\hline BXO160 & $z x x-1:: \operatorname{Tn} 5$ gusA11 rif- $11 ; \mathrm{Sp}^{\mathrm{r}}$, Gus $^{+}$derivative of $\mathrm{BXO} 43$ & Lab collection \\
\hline BXO1050 & BXO43/pUFR034 & Lab collection \\
\hline ВX0801 & vir-1 rif- $2 ; \mathrm{Eps}^{+}, \mathrm{Hrp}^{+}, \mathrm{Vir}^{-}, \mathrm{Xyn}^{-}$, derivative of $\mathrm{BXO} 43$ & This study \\
\hline BXO802 & $\mathrm{Eps}^{+}, \mathrm{Hrp}^{-}, \mathrm{Vir}^{-}, \mathrm{Xyn}^{+}$derivative of $\mathrm{BXO} 43$ & This study \\
\hline BXO803 & vir-1 rif-2/pUFR034; derivative of BXO801 & This study \\
\hline $\mathrm{BXO} 804$ & vir-1 rif-2/pSR1; $\mathrm{Vir}^{+}, \mathrm{Xyn}^{+}$derivative of $\mathrm{BXO} 01$ & This study \\
\hline BXO805 & xpsF1::Tn10 rif-2; $\mathrm{Vir}^{-}, \mathrm{Xyn}^{-}$derivative of $\mathrm{BXO} 43$ & This study \\
\hline BXO807 & xpsD1::Tn10 rif-2; $\mathrm{Vir}^{-}, \mathrm{Xyn}^{-}$derivative of $\mathrm{BXO} 43$ & This study \\
\hline BXO808 & vir-2::Tn5 gusA40rif-2; $\mathrm{Vir}^{-}, \mathrm{Xyn}^{+}$derivative of $\mathrm{BXO} 43$ & This study \\
\hline BXO809 & vir-3::Tn10 rif- $2 ; \mathrm{Vir}^{-}, \mathrm{Xyn}^{+}$derivative of $\mathrm{BXO} 43$ & This study \\
\hline BXO810 & xpsF1::Tn $10 / \mathrm{pSR} 1 ; \mathrm{Vir}^{+}, \mathrm{Xyn}^{+}$derivative of $\mathrm{BXO} 805$ & This study \\
\hline BXO811 & $x p s \mathrm{~F} 1:: \mathrm{Tn} 10 / \mathrm{pSR} 2 ; \mathrm{Vir}^{+}, \mathrm{Xyn}^{+}$derivative of $\mathrm{BXO} 805$ & This study \\
\hline BXO814 & xpsD1::Tn $10 / \mathrm{pSR} 1 ; \mathrm{Vir}^{+}, \mathrm{Xyn}^{+}$derivative of $\mathrm{BXO} 807$ & This study \\
\hline
\end{tabular}

${ }^{a}$ rif indicates a mutation that confers rifampicin resistance. vir indicates a mutation that causes virulence deficiency. Vir ${ }^{+}$indicates proficiency for virulence. $\mathrm{Eps}^{+}$indicates proficiency for extracellular polysaccharide production. Xyn ${ }^{+}$indicates proficiency for xylanase production. The chromosomal location of the $\mathrm{zxx}-1$ insertion has not been determined. 
plementation for virulence as well as xylanase production. This insertion also caused xylanase and virulence deficiency when marker exchanged in the BXO43 background (see Figure 1 for data obtained for virulence with BXO805, the xpsF1::Tn10 mutant). The full clone pSR1 and the subclone pSR2 containing the 3.5-kb EcoRI fragment restored virulence (Fig. 1) as well as xylanase proficiency when introduced into BXO805. Two other Tn10 insertions were found by sequence analysis to be at the same site as the $x p s \mathrm{~F} 1:: \mathrm{Tn} 10$ and behaved identically to this insertion in complementation and marker exchange studies. The other eight Tn 10 insertions did not affect complementation in BXO801 for either xylanase production or virulence. The marker exchange mutant with the insertion in the 6.2-kb EcoRI fragment (xpsD1; Fig. 3) exhibited virulence as well as xylanase deficiency (BXO807), similar to what was observed in BXO805 (data not shown). The full clone pSR1 restored virulence as well as xylanase secretion to BXO807. However, this insertion had no effect on the complementation ability of pSR1 to BXO801, suggesting that the mutation in the $6.2-\mathrm{kb}$ region was in a different complementation group than the insertions in the $3.5 \mathrm{~kb}$ region. Only five of the six Tn10 insertions ( $z x x-105$ to 108 and vir-3; Fig. 3) in the $11-\mathrm{kb}$ region could be marker exchanged and four of the marker exchange mutants remained proficient for virulence and xylanase secretion. However, one mutant (BXO809) was

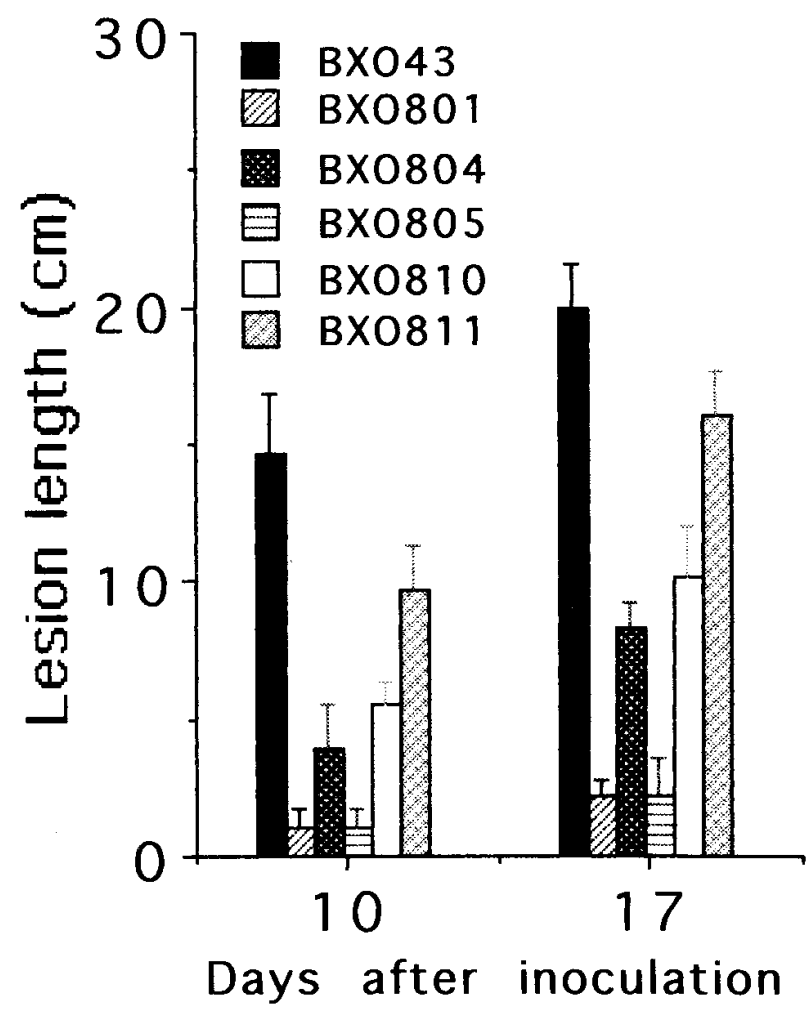

Fig. 1. Lesion lengths caused by strains of Xanthomonas oryzae pv. oryzae on susceptible rice cultivar TN-1, 10 and 17 days after inoculation. BXO43: the wild-type strain; BXO801: ethyl methane sulfonate (EMS)-induced $\mathrm{Vir}^{-}, \mathrm{Xyn}^{-}$mutant; BXO804: BXO801 strain containing pSR1; BXO805: xpsF-1::Tn10 marker exchange mutant; BXO810: $x p s \mathrm{~F} 1:: \operatorname{Tn} 10 / \mathrm{pSR} 1$; BXO811: xpsF1::Tn10/pSR2. Mean and standard deviation of 10 replicate measurements of lesion lengths are given. Similar results were obtained in independent experiments. reduced for virulence, causing lesion lengths of 3 and $7 \mathrm{~cm}$, 10 and 17 DAI, respectively, whereas the wild-type strain caused 15 and $24 \mathrm{~cm}$ lesions during the same time intervals. The xylanase secretion in the mutant was not affected. One insertion (isr-1) could not be marker exchanged (Fig. 3).

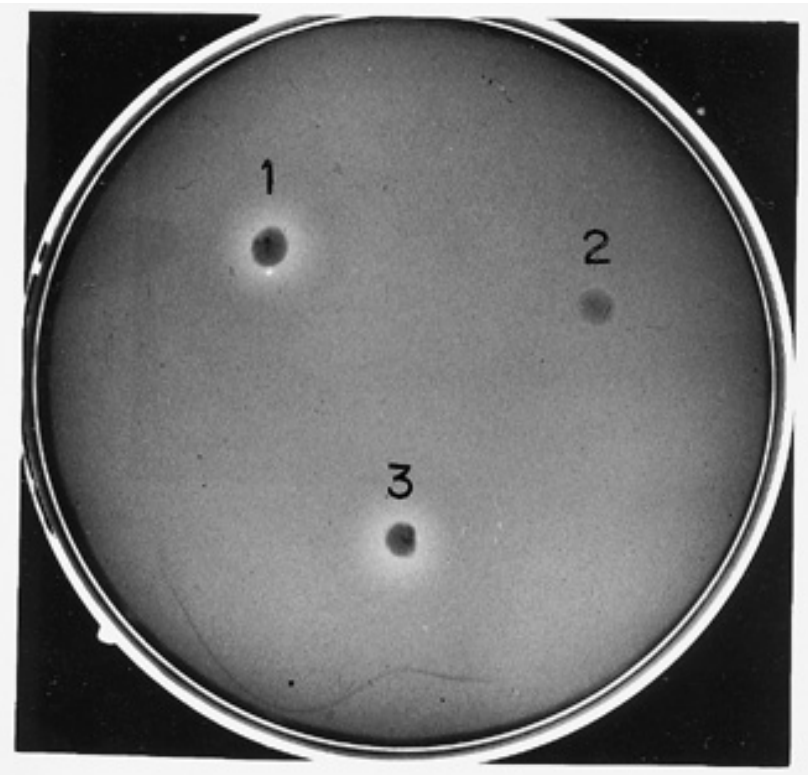

Fig. 2. Xylanase activity in strains of Xanthomonas oryzae pv. oryzae (Xoo). Peptone sucrose agar (PSA) + Km plates containing RBB-xylan with colonies of Xoo strains: 1, BXO1050 (wild-type strain carrying pUFR034); 2, BXO803 (vir-1/pUFR034); 3, BXO804 (vir-1/pSR1). Presence of halo around colony in BXO1050 and BXO804 indicates xylanase proficiency. This halo is very much reduced in BXO803.
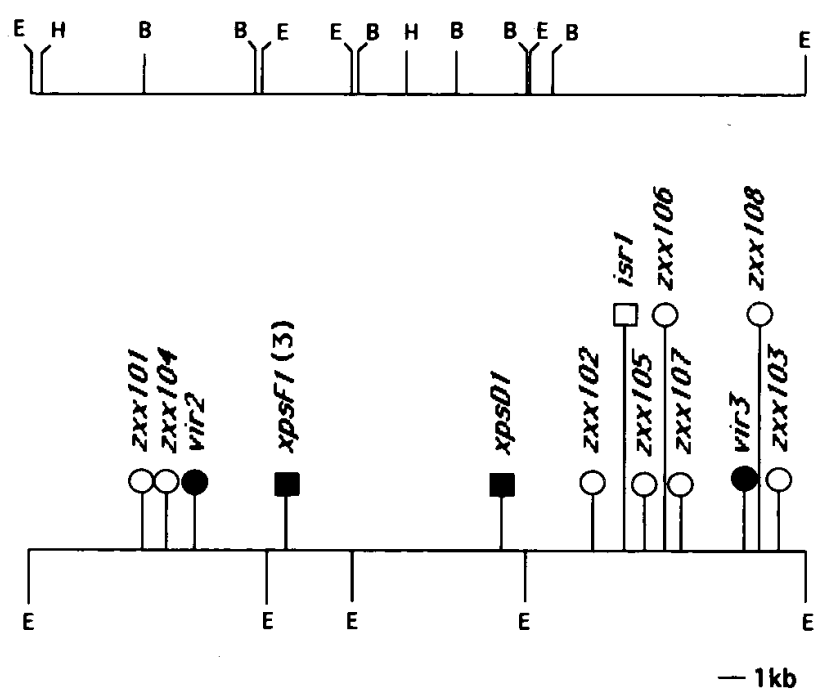

Fig. 3. Restriction map of pSR1 showing restriction sites for EcoRI (E), BamHI (B), and HindIII (H) and sites of Tn5 and Tn10 insertions. Filled squares, insertions that affect xylanase production and virulence; open circles, insertions that had no effect on either virulence or xylanase production; filled circles, insertions that affect only virulence; open square, an insertion that could not be marker exchanged. (3) indicates that three independent insertions of $\operatorname{Tn} 10$ were obtained at the same site in the $x p s \mathrm{~F}$ gene. 
Sequence analysis.

The flanking regions of the transposon insertions that caused virulence and xylanase deficiency when marker exchanged were sequenced with primers specific to the ends of the transposon (Fig. 4). Computer-based homology search was performed with the BLAST program (Altschul et al. 1990). The homology search showed that one insertion in the $3.5 \mathrm{~kb}$ $E c o R I$ fragment and another insertion on the $6.2-\mathrm{kb} E c o$ RI fragment were in the Xoo homologs of the $x p s \mathrm{~F}$ and $x p s \mathrm{D}$ genes of $X c c$, respectively. The nucleotide sequence and the derived amino acid sequence of the xpsFXo are shown in Figure 4A, with region of transposon insertion. For xpsFXo, the homology was about $85 \%$ at the nucleotide as well as at the protein level with $x p s F X c$. The partial nucleotide and derived amino acid sequence of $x p s \mathrm{DXo}$ is shown in Figure 4B. The homology at the nucleotide level for $x p s \mathrm{DXo}$ was not significant within the sequenced region except for a short stretch of 50 nucleotides, whereas there was $79 \%$ homology at the protein level within the stretch of 124 amino acids compared. The $x p s \mathrm{~F}$ and $x p s \mathrm{D}$ genes from $X c c$ encode components of a type II protein secretion system that is required for the secretion of pectinases, proteases,

A

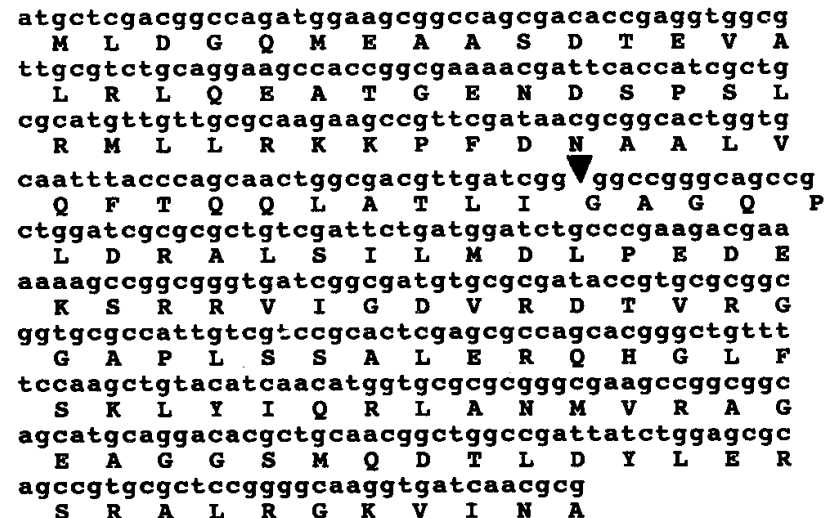

B

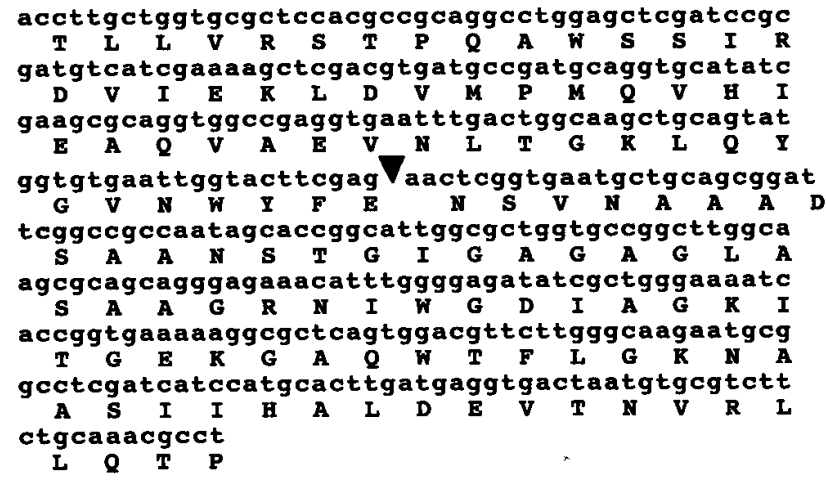

Fig. 4. A, Partial nucleotide sequence of the $x p s \mathrm{~F}$ gene of Xanthomonas oryzae pv. oryzae (Хoo). Deduced amino acid sequence is shown by single letter codes below. Triangle indicates site of the $x p s \mathrm{~F}: \mathrm{Tn} 10$ insertion. Partial nucleotide sequence is available at the GenBank database under accession number AF190908. B, Partial nucleotide and derived amino acid sequence of the xpsD gene of Xoo. Triangle indicates site of the $x p s \mathrm{D}:: \operatorname{Tn} 10$ insertion. Partial nucleotide sequence is available at the GenBank data base under accession number AF190907. and cellulases (Dums et al. 1991; Hu et al. 1992). Ongoing sequence analysis indicates that, as in Xcc, the xpsE homologue of Xoo is located adjacent to the $x p s F$ gene (data not shown).

Assay for xylanase activity and analysis of protein profiles in various cell fractions of wild-type and mutant strains of Xoo.

To show that the $x p s \mathrm{~F}$ gene from Xoo was involved in secretion of xylanase, the activity of xylanase was assayed in extracellular, periplasmic, and cytoplasmic fractions of the following strains: BXO803 (BXO801/pUFR034), BXO1050 (BXO43/pUFR034), BXO804 (BXO801/pSR1), BXO805 (xpsF-1::Tn10), BXO810 (xpsF-1::Tn10/pSR1). and BXO811 $(x p s \mathrm{~F}-1:: \mathrm{Tn} 10 / \mathrm{pSR} 2)$. The results are shown in Figure 5. Most of the xylanase activity was detected in the extracellular fraction of the wild-type strain (BXO1050), whereas periplasmic and cytoplasmic fractions showed very little activity. On the other hand, the mutant strain (BXO803) showed high activity in the periplasmic and cytoplasmic fractions and very little in the extracellular fraction. The BXO805 strain also exhibited a deficiency in xylanase transport. Xylanase activity was restored in the extracellular medium of BXO804, 810, and 811 strains (which contain the complementing clones). We introduced pUFR034 into the wild-type and mutant strains to show that the vector DNA does not affect xylanase secretion. We have performed similar assays on the xps D mutant and find that it exhibited similar deficiency for xylanase export (data not shown). These data suggest that xylanase is secreted by the type II protein secretion system in Xoo and that mutations in the xps genes affect its secretion, resulting in its accumulation in the periplasm and cytoplasm.

The proteins isolated from the extracellular and periplasmic fractions of BXO1050, BXO803, and BXO804 were analyzed

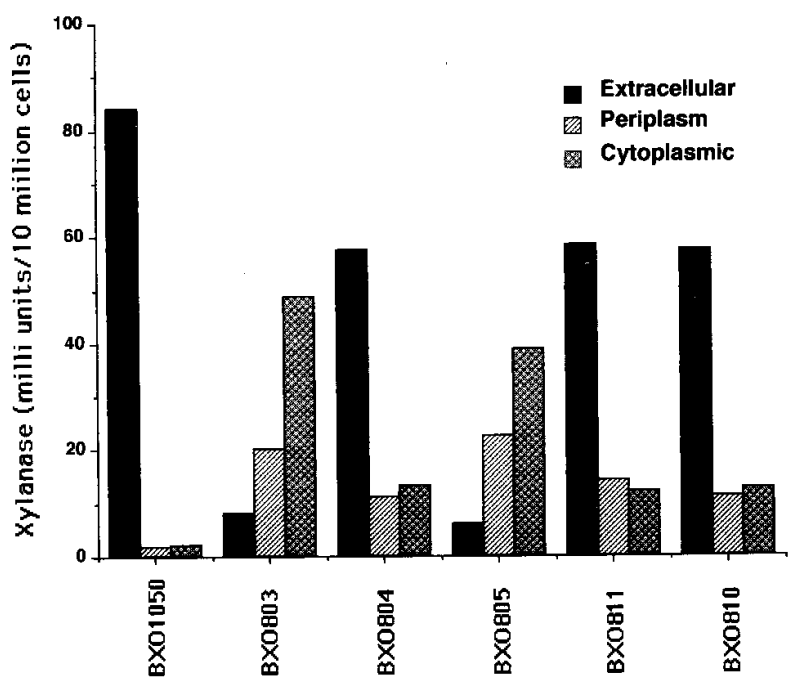

Fig. 5. Distribution of xylanase activity in various cellular fractions of Xanthomonas oryzae pv. oryzae (Xoo) strains. Proteins were precipitated with ammonium sulfate from various cellular fractions of the following Xoo strains and assayed for xylanase activity as described in Materials and Methods. BXO1050: wild-type strain carrying pUFR034; BXO803: BXO801/pUFR034; BXO804: BXO801/pSR1; BXO805: xpsF1::Tn10; BXO811: xpsF1::Tn10/pSR2; BXO810: xpsF1::Tn10/pSR1. Similar results were obtained in three independent experiments (data not shown). 
by sodium dodecyl sulfate-polyacrylamide gel electrophoresis (SDS-PAGE). Several prominent protein bands (approximately 55, 42, 35, 20, and $16 \mathrm{kDa}$ bands) were observed in the extracellular fraction of BXO1050 whereas the BXO803 strain showed very few proteins (Fig. 6). Some of these proteins were restored in the extracellular fraction of BXO804. These proteins were, however, present in the periplasmic fraction of BXO803, the most prominent being the $42-\mathrm{kDa}$ band (lane 6), which was absent in the periplasmic fraction of the wild-type strain (lane 5). The BXO804 strain showed bands similar to those of the mutant in the periplasmic fraction but the intensities of the bands, especially the $42 \mathrm{kDa}$ band, were comparatively low. This confirms the results of xylanase assays that show some xylanase activity in the periplasmic fraction of BXO804, suggesting that pSR1 is not fully restoring transport. The extracellular and periplasmic protein profiles of the $x p s \mathrm{~F} 1:: \operatorname{Tn} 10$ and $x p s \mathrm{D} 1:: \operatorname{Tn} 10$ insertion mutants were similar to that of BXO801 (data not shown).

\section{Lack of in planta complementation of xps mutants by the wild-type strain of Xoo.}

Differentially marked wild-type and mutant strains of Xoo were mixed in a 1:1 ratio and coinoculated in various combinations onto rice leaves by the leaf clip method described in Materials and Methods. The bacterial colonies were recovered from the lesion ends 15 DAI (see Materials and Methods) and assayed for the respective markers. In one combination, a $\beta$ glucuronidase (GUS)-marked derivative of BXO43 (BXO160, $\mathrm{Xps}^{+}$and $\mathrm{Vir}^{+}$) was coinoculated with BXO801 at a ratio of 1:1. The recovered colonies were assayed for gus activity as described in Materials and Methods. Of the 150 individual colonies tested, all were found to be gus positive, indicating the presence of only the $\mathrm{Xps}^{+}$strain. On the other hand, when the $\mathrm{Hrp}^{-}$mutant, BXO802, was coinoculated with BXO160,

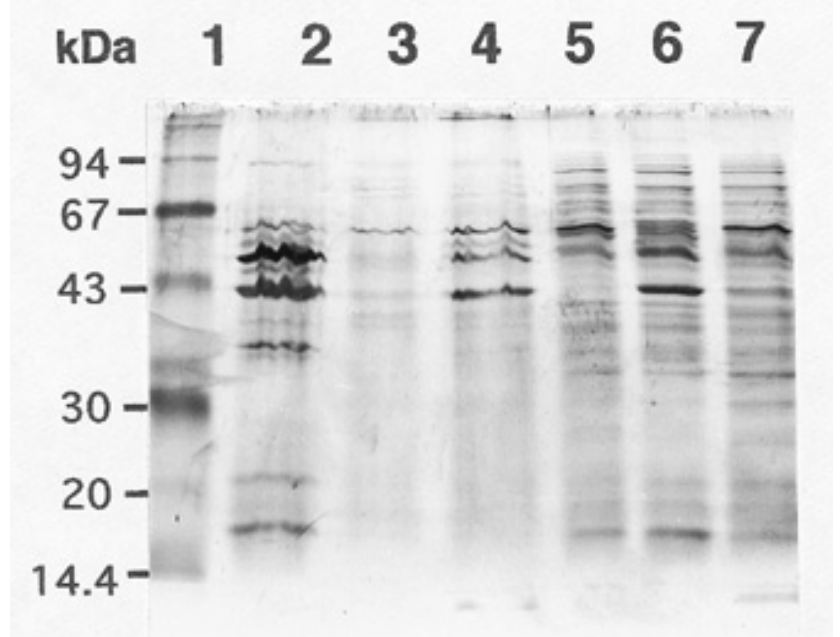

Fig. 6. Analysis of extracellular (lanes 2-4) and periplasmic (lanes 5-7) protein fractions from different strains of Xanthomonas oryzae pv. oryzae by sodium dodecyl sulfate-polyacrylamide gel electrophoresis (SDS-PAGE). Gels were stained by silver staining as described in Materials and Methods. Lane 1, molecular mass markers (Bio-Rad, Hercules, CA). Lanes 2 and 5, BXO1050 (wild-type strain carrying pUFR034); lanes 3 and 6, BXO803 (BXO801/pUFR034); lanes 4 and 7, BXO804 (BXO801/pSR1). Similar results were obtained in three independent experiments and when xpsF::Tn10 or xpsD::Tn10 insertion mutants were used instead of BXO801. for every 150 colonies assayed for gus activity 30 colonies were found to be gus negative and therefore of the Hrp ${ }^{-}$mutant type. In planta complementation of an $\mathrm{Hrp}^{-}$mutant of Xoo by an $\mathrm{Hrp}^{+}$strain has been previously demonstrated by Leach et al. (1996).

In another set of experiments, the BXO1 $\left(\mathrm{Rf}^{\mathrm{s}}\right)$ strain was coinoculated at a ratio of 1:1 with either BXO801 $\left(\mathrm{Rf}^{\mathrm{r}}\right)$ or BXO805 (xpsF1::Tn10; $\mathrm{Rf}^{\mathrm{r}}$ and $\mathrm{Tc}^{\mathrm{r}}$ ). Fifteen DAI, bacteria were isolated from the leading edge of the lesion (see Materials and Methods) and plated on PSA and PSA plus Rf plates. About 10 colonies on PSA + Rf plates and approximately 10,000 colonies on PSA plates were obtained from leaves inoculated with the BXO1 + BXO801 mixture. This indicates the presence of one colony of $\mathrm{Xps}^{-}$mutant type for every 1,000 colonies of the $\mathrm{Xps}^{+}$strain. Similar ratios were obtained when BXO1 was coinoculated with the marker-exchange $\mathrm{Xps}^{-}$ mutant, BXO805. A mixture of BXO1 and BXO43 resulted in a 1:1 ratio of $\mathrm{Rf}^{\mathrm{r}}: \mathrm{Rf}^{\mathrm{s}}$ colonies, indicating that $\mathrm{Rf}$ marker did not affect growth in planta. However, when BXO1 was coinoculated with the Hrp ${ }^{-}$mutant BXO802, 2,000 $\mathrm{Rf}^{\mathrm{r}}$ colonies were observed for every 10,000 colonies, indicating a ratio of 1:4 of the $\mathrm{Hrp}^{-}$mutant type to the $\mathrm{Hrp}^{+}$strain. These data suggest that the virulence function defective in BXO801 and BXO805 could not be efficiently complemented by any factor produced in trans by the wild-type cell and is therefore likely to affect individual bacterial cells.

\section{DISCUSSION}

Phytopathogenic bacteria produce extracellular enzymes like cellulases, pectinases, proteases, and xylanases. These enzymes are secreted to the extracellular environment by the general secretory pathway (GSP) (Dow et al. 1987; Hu et al. 1992; He et al. 1991), which is also called the type II protein secretion system (Salmond et al. 1993; Russel 1998). The GSP is the protein secretion system that secretes proteins from cytosol to extracellular environment in two steps. In step 1, the proteins are secreted from the cytoplasm to the periplasm by sec gene products. This is called the general export pathway (GEP). In step 2, the proteins are secreted from the periplasm to the extracellular medium through the outer membrane by a complex assembly of proteins. This is called the main terminal branch (MTB) of the GSP (Pugsley 1993; Pugsley et al. 1997). Mutants of X. campestris unable to secrete various enzymes to the extracellular medium due to mutation in the MTB of the GSP are virulence deficient and accumulate enzymes in the periplasm (Dow et al. 1987; Hu et al. 1992), similar to BXO801 and BXO805 (xpsF1::Tn10) mutants of Xoo reported in this study. It is not known whether the virulence deficiency in $X$. campestris is due to the absence of these enzymes in the extracellular milieu or some other virulence factors secreted by the GSP. The direct involvement of these enzymes in virulence is not defined because several studies (Dow et al. 1989; Tang et al. 1987) have shown that mutants defective in production of particular extracellular enzymes are virulence proficient. However, one possible reason for the virulence proficiency of these mutants may be that other extracellular enzymes performed the necessary functions.

Rice plant cell walls contain $60 \%$ xylan (Takeuchi et al. 1994) and the ability to degrade xylan may be an important 
attribute of a rice pathogen. However, from the previous reports the role of xylanase as a virulence factor is not very clear. The fungal pathogen of rice, Magnaporthe grisea, produces xylanase, and xylanase knockout mutants of this pathogen had no effect on virulence but it was found that other isozymes were also being produced by the pathogen (Wu et al. 1995). Also, xylanase-deficient mutants of Erwinia chrysanthemi, which affects corn (Keen et al. 1996), have been shown to be virulence proficient. Interestingly, xylanase from Trichoderma viridae and $T$. reese $i$ has been shown to have elicitor functions since it is able to induce hypersensitive cell death in cell cultures of certain tobacco lines (Yano et al. 1998). We have cloned the xylanase structural gene of Xoo (data not shown) and are constructing specific marker exchange mutants to determine the role of xylanase in virulence of Xoo.

As shown by protein profiles, xylanase is not the only protein (enzyme) whose secretion is affected by a mutation in the MTB of Xoo. Some of these other proteins may also be playing an important role in virulence. The observation that the $x p s \mathrm{~F}$ mutants are not complemented for virulence by coinoculation with the wild type suggests that some other virulence functions might be secreted through the MTB that are restricted to cells that possess them. One possibility may be that MTB is required for secretion of a pilus or adhesin that is essential for Xoo virulence.

The Tn5-induced MTB mutants of Xcc were shown to accumulate polygalacturonate lyase and $\alpha$-amylase enzymes in their periplasm but no enzyme was detected in the cytoplasm (Hu et al. 1992). In our study, we find that xylanase not only accumulates in the periplasm but also can be detected in the cytoplasmic fraction. This suggests the possibility that mutation in the xps genes of Xoo may affect, either directly or indirectly, the transport of certain secreted proteins from the cytoplasm to the periplasm. Alternatively, the possibility of contamination between the two fractions during extraction of cellular fractions cannot be ruled out.

Earlier workers had reported a cluster of genes from Xoo that were iso-functional with those encoding type II secretion proteins in Xcc and could complement for pathogenicity and production of proteases in Xcc mutants (Todd et al. 1990). They, however, did not characterize these genes for their role in virulence of Xoo. In our study, we conclusively show that mutations in the MTB of the GSP affect virulence as well as secretion of xylanase and several other proteins in Xoo. The role of specific secreted proteins in virulence of Xoo remains to be determined.

\section{MATERIALS AND METHODS}

\section{Bacterial strains, plasmids, and culture media.}

The source and characteristics of the bacterial strains and plasmids used in this study are shown in Table 1. Escherichia coli cells were cultured on LB medium (Miller 1992) at $37^{\circ} \mathrm{C}$ and Xoo cultures were grown on peptone sucrose agar (PSA; Tsuchiya et al. 1982) medium at $28^{\circ} \mathrm{C}$. The minimal medium used for growing Xoo was modified Miller's minimal medium (M4; Kelemu and Leach 1990). Nutrient agar (NA) medium contained $23 \mathrm{~g}$ of nutrient agar (Difco, Detroit, MI) per liter of water.

Antibiotics used in this study were as follows: kanamycin (Km) $50 \mathrm{mg} / \mathrm{liter}$ for $E$. coli and $25 \mathrm{mg} / \mathrm{liter}$ for Xoo; cephalexin (Cp) $20 \mathrm{mg} / \mathrm{liter}$; tetracycline (Tc) $10 \mathrm{mg} / \mathrm{liter}$ for E. coli and $5 \mathrm{mg} / \mathrm{liter}$ for Xoo; rifampicin (Rf) $50 \mathrm{mg} / \mathrm{liter}$.

\section{EMS mutagenesis of Xoo.}

EMS (Sigma Chemical, St. Louis, MO) mutagenesis of Xoo was as described for E. coli by Miller (1992). Twenty microliters of a cell suspension from mutagenized and washed Xoo cells was inoculated in $2 \mathrm{ml}$ of PS and incubated at $28^{\circ} \mathrm{C}$ for $48 \mathrm{~h}$ before the cells were dilution plated for single colonies on PSA plates. Individual Eps-proficient colonies that appeared on the plates were used for virulence assays.

\section{Virulence assays.}

Virulence assays were performed on 40- to 60-day-old plants of the highly susceptible rice cultivar Taichung Native -1 (TN-1) by the leaf clipping method of inoculation (Kauffman et al. 1973). Saturated cultures of Xoo grown in PS medium were pelleted down, resuspended in water at a density of $10^{9}$ cells per ml. Scissors dipped in this inoculum were used to clip the tips of rice leaves. Symptoms were scored by measuring lesion lengths at regular intervals. Strains that either did not cause lesions or formed smaller lesions on TN-1 leaves after repeated inoculation were considered to be virulence deficient $\left(\mathrm{Vir}^{-}\right)$.

\section{Reisolation of bacteria from infected rice leaves.}

Infected leaves were surface sterilized by dipping in $2 \%$ (vol/vol) sodium hypochlorite (Loba Chemie, Mumbai, India) for $2 \mathrm{~min}$ and washing twice in sterile water. The leaves were cut at the leading edge of the lesion and dipped in $1 \mathrm{ml}$ of sterile water for $2 \mathrm{~min}$. Bacteria that exuded from the cut edge of the leaf were isolated by plating for individual colonies on appropriate medium.

\section{HR test on tomato leaves.}

Saturated cultures of Xoo prepared as for virulence assays were infiltrated into leaves of greenhouse-grown tomato plants of cv. Pusa Ruby (suppliers: Maharashtra Hybrid Seeds, Jalgaon, India) with a needle and hypodermic syringe. HRs elicited by Xoo in the form of necrotic regions at the site of inoculation were observed within 24 to $48 \mathrm{~h}$ of infiltration.

\section{GUS assays.}

GUS activity of bacterial colonies was assayed by staining with 4-methyl umbelliferyl $\beta$-glucuronide (MUG, Sigma Chemical) and visualized under UV light as described by Jefferson et al. (1987).

\section{Bacterial conjugation.}

Matings between $E$. coli strains were done by growing cultures of each of the donor and recipient strains in LB medium containing the required antibiotics for $24 \mathrm{~h}$ at $37^{\circ} \mathrm{C}$, washing the cells with sterile water, and resuspending in the original volume of sterile water. The cells were mixed in the ratio of $1: 1(\mathrm{vol} / \mathrm{vol})$ and $0.1 \mathrm{ml}$ of the mixture was spotted on $\mathrm{N}^{+}$membrane (Amersham Life Sciences, Buckinghamshire, UK) placed on LB agar. Following incubation for $24 \mathrm{~h}$ at $37^{\circ} \mathrm{C}$, the cells were removed from the membrane with sterile toothpicks into $1 \mathrm{ml}$ of sterile, distilled water, plated on selection media, and incubated at $37^{\circ} \mathrm{C}$ for $24 \mathrm{~h}$ to obtain transconjugants. 
For mating between E. coli as the donor and Xoo as the recipient strain, E. coli cells were prepared as described above. Xoo cultures were grown to saturation in PS medium for $48 \mathrm{~h}$ at $28^{\circ} \mathrm{C}$, following which the cells were pelleted and resuspended in one-hundredth the original volume of sterile water. Matings were performed by mixing the above cultures of donor and recipient at a ratio of $1: 10(\mathrm{vol} / \mathrm{vol})$ and spotting 0.1 $\mathrm{ml}$ on $\mathrm{N}^{+}$membrane overlaid on NA. After $48 \mathrm{~h}$ of incubation at $28^{\circ} \mathrm{C}$, cells were removed from the membrane and plated on selection media.

\section{Isolation of complementing clone by functional complementation.}

A partial EcoRI-digested genomic library of our laboratory wild-type Xoo strain, having an average insert size of $30 \mathrm{~kb}$, has been made (Rajagopal et al. 1995) in the broad-host-range cosmid cloning vector pUFR034 (Km ${ }^{\mathrm{r}}$; DeFeyter et al. 1990). Nine hundred sixty clones from this library were transferred from E. coli strains DH5 $\alpha$ to S17-1 with pRK600 as a helper (L. Rajagopal, S. Dharmapuri, and R. V. Sonti, unpublished results). Genomic clones from the above library in S17-1 were mobilized, in pools of 12 clones each, into the virulencedeficient mutant by biparental matings. Transconjugants that appeared on PSA plus Km and Rf selection plates were pooled together in $1 \mathrm{ml}$ of sterile water and inoculated on $\mathrm{TN}-1$ rice plants to identify clones that restored virulence.

\section{Assay for extracellular enzymes.}

Assays for xylanase secretion were performed as described by Keen et al. (1996). Xoo colonies were spotted on PSA containing $0.2 \% \mathrm{RBB}-x y l a n$ (Sigma Chemical). A white halo surrounding the colonies against the blue background of the plate indicated secretion of xylanase. Xoo strains unable to produce xylanase did not show the halo. Quantitation of xylanase in different cellular fractions was done according to the procedure described by Biely et al. (1988).

Assays for extracellular cellulases, pectinases, and proteases were done by the procedure described by Tsuchiya et al. (1982), with some modifications as per Andro et al. (1984).

\section{Transposon mutagenesis and marker exchange.}

Transposon mutagenesis of the cloned DNA was performed with either mini Tn5 (Wilson et al. 1995) or mini Tn10 dTet derivative (Kleckner et al. 1991). Tn5 mutagenesis of the cloned DNA was done by mobilizing a suicide plasmid carrying the transposon Tn5gus A40 (Wilson et al. 1995) into the $\mathrm{DH} 5 \alpha$ strain having the cloned DNA (pSR1), by conjugation. Transconjugants were selected on LB agar plates containing kanamycin and spectinomycin. To identify insertions on plasmid DNA, transconjugants were conjugated with another $E$. coli strain (CAG18431, strain list) and selected on LB agar plates containing spectinomycin, kanamycin, and tetracycline. For Tn10 mutagenesis, lysates of $\lambda$ NK1323 containing the mini Tn10 transposon (Kleckner et al. 1991) were prepared on the LE392 strain of E. coli as described by Miller (1992). The MC4100 strain of E. coli carrying the pSR1 plasmid was grown for $24 \mathrm{~h}$ at $37^{\circ} \mathrm{C}$ in $1 \mathrm{ml}$ of $\mathrm{LB}$ medium containing $0.4 \%$ maltose and kanamycin. The cells were subcultured in $10 \mathrm{ml}$ of the above medium and grown at $37^{\circ} \mathrm{C}$ till $A_{600}$ was 0.6 to 0.8 . To $2 \mathrm{ml}$ of this culture containing approximately 1 $\times 10^{9}$ cells, $10 \mathrm{ml}$ of $\lambda \mathrm{NK} 1323$ lysate (with a titer of $1 \times 10^{10}$ per $\mathrm{ml}$ ) was added and the culture was incubated at $37^{\circ} \mathrm{C}$ for $20 \mathrm{~min}$. The culture was centrifuged at $10,000 \times g$ for $5 \mathrm{~min}$ and the pellet was washed with $0.1 \mathrm{M}$ citrate buffer ( $\mathrm{pH}$ 5.5). The cells were resuspended in $5 \mathrm{ml}$ of LB medium containing $20 \mathrm{mM}$ sodium pyrophosphate, incubated at $37^{\circ} \mathrm{C}$ for $2 \mathrm{~h}$, diluted in $40 \mathrm{ml}$ of LB medium containing kanamycin and tetracycline, $25 \mathrm{mM}$ sodium pyrophosphate, and incubated overnight at $37^{\circ} \mathrm{C}$. Cells were pelleted and then conjugated with DH5 $\alpha$ with a helper strain containing pRK600. Transconjugants were obtained on LB agar plates containing kanamycin, nalidixic acid, and tetracycline. Plasmid was isolated from these transconjugants and digested with EcoRI to localize the transposon insertions on either vector or insert DNA. Transposon insertions in the insert DNA were further mapped with HindIII and BamHI. These pSR1 derivatives were mobilized into BXO801 for complementation assays and BXO043 for marker exchange. Marker exchange was done by growing the cells in either PS+Tet medium (for Tn10 dTet) or in PS+Sp (for mini $\mathrm{Tn} 5$ ) for more than 30 generations by serial passage. Tet or Sp resistant and $\mathrm{Km}$ sensitive ( $\mathrm{Km}$ is the marker on the vector) colonies were analyzed by Southern hybridization to confirm that marker exchange had occurred as expected.

\section{Plasmid isolation and DNA sequencing.}

Plasmid DNA was isolated by the alkaline lysis method as described in Sambrook et al. (1989). Restriction digestions were done, as required, with enzymes obtained from NEB (New England Biolabs, Beverly, MA), as per the supplier's instruction. Sequencing of the Tn 10 insertions was performed with primers $5^{\prime}$-TGGTCACCAACGCTTTTCCCGAG-3' and 5'-CTGTTGACAAAGGGAATCATAG-3', directed outwardly from Tn10. The sequencing reactions, electrophoresis, and sequence data analysis were performed with the ABI Prism 377 automated DNA sequencer (Perkin Elmer, Norwalk, CT).

\section{Cellular fractionation.}

Different cellular fractions were obtained as described by Hu et al. (1992). Saturated cultures of Xoo strains were centrifuged at $17,000 \times g$ for $10 \mathrm{~min}$. The supernatant was taken as the extracellular fraction. The pellet was washed twice with equal volumes of water and then treated on ice for $2 \mathrm{~h}$ with lysozyme $(200 \mathrm{mg} / \mathrm{ml})$ in a solution made up of $20 \%$ sucrose, $30 \mathrm{mM}$ Tris- $\mathrm{HCl}$ (pH8.0), and $1 \mathrm{mM}$ EDTA. The lysozymetreated cells were pelleted by centrifugation at $25,000 \times g$ for $10 \mathrm{~min}$. The supernatant was collected as the periplasmic fraction. The cell pellet was resuspended in $10 \mathrm{mM}$ Tris- $\mathrm{HCl}$ ( $\mathrm{pH} 8.0)$, passed through a 24-gauge needle, and centrifuged at $25,000 \times g$ for $15 \mathrm{~min}$. The supernatant was collected as the cytoplasmic fraction. Each of the above fractions was precipitated by $50 \%(\mathrm{wt} / \mathrm{vol})$ ammonium sulfate and centrifuged at $12,000 \times g$ for $10 \mathrm{~min}$. The pellets were dissolved in onetenth the original volume of acetate buffer and assayed for xylanase activity as described above.

\section{Analysis of proteins from various cellular fractions by SDS-PAGE.}

Proteins isolated from various cellular fractions were analyzed by SDS-PAGE by the method of Laemmli (1970). The gels were stained with silver nitrate as described by Sambrook et al. (1989). The molecular mass markers used were obtained from Pharmacia Biotechnology (Uppsala, Sweden). 


\section{ACKNOWLEDGMENTS}

S. K. R. was supported by a senior research fellowship from the Council of Scientific and Industrial Research (CSIR), Government of India.

\section{LITERATURE CITED}

Altschul, S. F., Gish, W., Myers, E. W., and Lipman, D. J. 1990. Basic local alignment search tool. J. Mol. Biol. 215:403-410.

Andro, T., Chambost, J.-P., Kotoujansky, A., Cattaneo, J., Bertheau, Y., Barras, F., van Gijsegem, F., and Coleno, A. 1984. Mutants of Erwinia chrysanthemi defective in secretion of pectinase and cellulase. J. Bacteriol. 160:1199-1203.

Biely, P., Mislovicova, D., and Toman, R. 1988. Remazol brilliant blue xylan: A soluble chromogenic substrate for xylanase. Pages 633-634 in: Methods in Enzymology. Vol. 160. W. A. Wood, and S. T. Kellog, eds. Academic Press, San Diego, CA.

DeFeyter, R., Kado, C. I., and Gabriel, D. W. 1990. Small stable shuttle vectors for use in Xanthomonas. Gene. 88:65-72.

Dow, J. M., Milligan, D. E., Jaison, L., Barber., C. E., and Daniels, M. J. 1987. A gene cluster in Xanthomonas campestris required for pathogenicity controls the excretion of polygalacturonate lyase and other enzymes. Physiol. Mol. Plant Pathol. 31:261-271.

Dow, J. M., Milligan, D. E., Jaison, L., Barber, C. E., and Daniels, M. J. 1989. Molecular cloning of a polygalacturonate lyase gene from Xanthomonas campestris pv. campestris and role of the gene product in pathogenicity. Physiol. Mol. Plant Pathol. 35:113-120.

Dums, F., Dow, J. M., and Daniels, M. J. 1991. Structural characterization of protein secretion genes of the bacterial phytopathogen Xanthomonas campestris pathovar campestris: Relatedness to secretion systems of other gram negative bacteria. Mol. Gen. Genet. 229:357364.

He, S. Y., Lindeberg, M., Chatterjee, A. K., and Collmer, A. 1991. Cloned Erwinia chrysanthemi out genes enable Escherichia coli to selectively secrete a diverse family of heterologous proteins to its milieu. Proc. Natl. Acad. Sci. USA 88:1079-1083.

Hu, N. T., Hung, M. N., Chiou, S. J., Tang, F., Chiang, D. C., Huang, H. Y., and Wu, C. Y. 1992. Cloning and characterization of a gene required for the secretion of extracellular enzymes across the outer membrane by Xanthomonas campestris pv. campestris. J. Bacteriol. 174:2679-2687.

Jefferson, R. A., Kavanagh, T. A., and Bevan., M. W. 1987. GUS fusions, $\beta$-glucuronidase as a sensitive and versatile marker in higher plants. EMBO J. 6:3901-3907.

Kamdar, H. V., Kamoun, S., and Kado, C. I. 1993. Restoration of pathogenicity of avirulent Xanthomonas oryzae pv. oryzae and X. campestris pathovars by reciprocal complementation with the hrpXo and hrpXc genes and identification of HrpX function by sequence analyses. J. Bacteriol. 175:2017-2025.

Kauffman, H. E., Reddy, A. P. K., Hsieh, S. P. Y., and Merca, S. D. 1973 An improved technique for evaluation of resistance of rice varieties to Xanthomonas oryzae. Plant Dis. Rep. 57:537-541.

Keen, N. T., Boyd, C., and Henrissat, B. 1996. Cloning and characterization of a xylanase gene from corn strains of Erwinia chrysanthemi. Mol. Plant-Microbe Interact. 9:651-657.

Kelemu, S., and Leach, J. E. 1990. Cloning and characterization of an avirulence gene from Xanthomonas campestris pv. oryzae. Mol. Plant-Microbe Interact. 3:59-65.

Kleckner, N., Bender, J., and Gottesman, S. 1991. Uses of transposons, with emphasis on Tn10. Pages 139-180 in: Methods in Enzymology. Vol. 204. W. A. Wood and S. T. Kellog, eds. Academic Press, San Diego, CA.

Laemmli, U. K. 1970. Cleavage of structural proteins during the assembly of the head of bacteriophage T4. Nature 227:680-685.

Leach, J. E., Zhu, W., Chittor, J. M., Ponciano, G., Young, S. A., and White, F. F. 1996. Genes and proteins involved in aggressiveness and avirulence of Xanthomonas oryzae pv. oryzae to rice. Pages 191-196 in: Biology of Plant-Microbe Interactions: Proc. Int. Symp. Mol. Plant-Microbe Interact., 8th.

Miller, J. H. 1992. A Short Course in Bacterial Genetics: A Laboratory Manual for Escherichia coli and Related Bacteria. Cold Spring Harbor Laboratory, Cold Spring Harbor, NY.
Pugsley, A. P. 1993. The complete general secretory pathway in gramnegative bacteria. Microbiol. Rev. 57:50-108.

Pugsley, A. P., Francetic, O., Possot, O. M., Sauvonnet, N., and Hardie, K. R. 1997. Recent progress and future directions in studies of the main terminal branch of the general secretory pathway in gramnegative bacteria - a review. Gene 192:13-19.

Rajagopal, L., Jamir, Y., Dharmapuri, S., Karunakaran, M., Ramanan, R., Reddy, A. P. K., and Sonti, R. V. 1995. Molecular genetic studies of the bacterial leaf blight pathogen of rice in India. Pages 939-944 in: Rice Genetics III. Proc. Int. Rice Genet., 3rd. IRRI, Manila, Philippines.

Rajeshwari, R., Yashitola, J., Reddy, A. P. K., and Sonti, R. V. 1997. Characteristics of stationary-phase variation affecting virulence in Xanthomonas oryzae pv. oryzae. Can. J. Microbiol. 43:862-867.

Roberts, D. P., Denny, T. P., and Schell, M. A. 1988. Cloning of the egl gene of Pseudomonas solanacearum and analysis of its role in phytopathogenicity. J. Bacteriol. 170:1445-1451.

Russel, M. 1998. Macromolecular assembly and secretion across bacterial cell envelope: Type II protein secretion systems. J. Mol. Biol. 279:485-499.

Salmond, G. P. C., and Reeves, P. J. 1993. Membrane traffic wardens and protein secretion in Gram-negative bacteria. TIBS 18:7-12.

Sambrook, J., Fritsch, E. F., and Maniatis, T. A. 1989. Molecular Cloning: A Laboratory Manual. Cold Spring Harbor Laboratory, Cold Spring Harbor, NY.

Schell, M. A., Roberts, D. P., and Denny, T. P. 1988. Analysis of the Pseudomonas solanacearum polygalacturonase encoded by $p g l \mathrm{~A}$ and its involvement in phytopathogenicity. J. Bacteriol. 170:45014508.

Simon, R., Priefer, U., and Puhler, A. 1983. A broad host range mobilization system for in vivo genetic engineering: Transposon mutagenesis in gram negative bacteria. Biotechnology 1:784-791.

Singer, M., Baker, T. A., Schnitzler, G., Deischel, S. M., Goel, M., Dove, W., Jaacks, K. J., Grossman, A. D., Erickson, J. W., and Gross, C. A. 1989. A collection of strains containing genetically linked alternating antibiotic resistance elements for genetic mapping of Escherichia coli. Microbiol. Rev. 53:1-24.

Tang, J.-L., Feng, J.-X., Li, Q.-Q., Wen, H.-X., Zhou, D.-L., Wilson, T. J. G., Dow, J. M., Ma, Q.-S., and Daniels, M. J. 1996. Cloning and characterization of the rpfC gene of Xanthomonas oryzae pv. oryzae: Involvement in exopolysaccharide production and virulence to rice. Mol. Plant-Microbe Interact. 9:664-666.

Tang, J.-L., Gough, C. L., Barber, C. E., Dow, J. M., and Daniels, M. J. 1987. Molecular cloning of protease gene(s) from Xanthomonas campestris pv. campestris: Expression in Escherichia coli and role in pathogenicity. Mol. Gen. Genet. 210:443-448.

Takeuchi, Y., Tohbaru, M., and Sato, A. 1994. Polysaccharides in primary cell walls of rice cells in suspension culture. Phytochemistry 35: 361-363.

Todd, G. A., Daniels, M. J., and Callow, J. A. 1990. Xanthomonas campestris pv. oryzae has DNA sequences containing genes isofunctional with $X$. campestris pv. campestris genes required for pathogenicity. Physiol. Mol. Plant Pathol. 36:73-87.

Tsuchiya, K., Mew, T. W., and Wakimoto, S. 1982. Bacteriological and pathological characteristics of wild types and induced mutants of Xanthomonas campestris pv. oryzae. Phytopathology 72:43-46.

White, F. F., Chittoor, J. M., Leach, J. E., Young, S. A., and Zhu, W. 1995. Molecular analysis of the interaction between Xanthomonas oryzae pv. oryzae and rice. Pages 255-266 in: Rice Genetics III. Proc. Int. Rice Genet. Symp., 3rd. IRRI, Manila, Philippines.

Wilson, K. J., Sessitsch, A., Corbo, J. C., Giller, K. E., Akkermans, A D. L., and Jefferson, R. A. 1995. $\beta$-Glucuronidase (GUS) transposons for ecological and genetic studies of rhizobia and other gram-negative bacteria. Microbiology 141:1691-1705.

Wu, S. C., Kauffmann, S., Darvill, A. G., and Albersheim, P. 1995. Purification, cloning and characterization of two xylanases from Magnaporthe grisea, the rice blast fungus. Mol. Plant-Microbe Interact. 8: 506-514.

Yamasaki, Y., Murata, N., and Suwa, T. 1964. The effect of mutations for nutritional requirements on the pathogenicity of two pathogens of rice. Proc. Jpn. Acad. 40:226-231.

Yano, A., Suzuki, K., Uchimiya, H., and Shinshi, H. 1998. Induction of hypersensitive cell death by a fungal protein in cultures of tobacco cells. Mol. Plant-Microbe Interact. 11:115-123. 